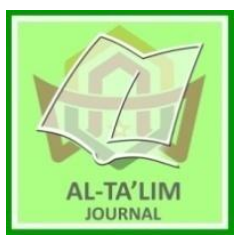

AL-TA'LIM JOURNAL, 26 (3), 2019, (309-317)

(Print ISSN 1410-7546 Online ISSN 2355-7893)

Available online at http://journal.tarbiyahiainib.ac.id/index.php/attalim

\title{
Promoting Photovoice for Teachers' Self-Reflection on Multimodal Literacy
}

Received: $28^{\text {th }}$ August 2019; Revised: $30^{\text {th }}$ January 2019; Accepted: $30^{\text {th }}$ November 2019

Permalink/DOI: http://dx.doi.org/10.15548/jt.v26i3.513

\section{Nur Arifah Drajati*)}

Universitas Sebelas Maret, Surakarta, Indonesia

E-mail:Nurarifah_drajati@staff.uns.ac.id

\section{Ngadiso}

Universitas Sebelas Maret, Surakarta, Indonesia

Email: ngadiso@gmail.com

\section{Hasan Zainnuri}

Universitas Sebelas Maret, Surakarta, Indonesia

Email: hasanzainnuri@uns.ac.id

\section{*) Corresponding Author}

\begin{abstract}
Self-reflection is a concept of learning from experience that dominates teacher educator around the world. It is true that selfreflective is not a natural process since it needs critical thought, selfdirection, and problem-solving with personal knowledge and selfawareness. The major premise of the study is that although teachers are repeatedly encouraged to reflect on their teaching and learning, they are unable to do so successfully. Photovoice is a valuable tool to engage teachers in reflecting their own lives outside the school voice their perspectives and share with other teachers, students, and policymakers. Thus, the purpose of this study is to report on action research that investigated photovoice in emerging teachers' self-reflective on multimodal literacy. To examine this issue, a qualitative study with an action research design was conducted with five junior high school teachers as participants. The data collected through photovoice and analyzed by using SHoWeD Analysis. SHoWeD analysis is the acronym for a series of questions: (1) what do you see here; (2) what is happening; (3) how does this relate to our lives; (4) why are things this way; (5) how could this image educate people. In general, the study indicates that the use of photovoice for self-reflective on multimodal literacy gives positive impacts on the context of teacher professional development.
\end{abstract}

Keywords: Photovoice; self-reflection; teachers continued professional development.

How to Cite: Drajati, N. (2020). Promoting photovoice for teachers' self-reflection on multimodal literacy. AlTa Lim Journal, 26(3). doi:http://dx.doi.org/10.15548/jt.v26i3.513

\section{INTRODUCTION}

Self-reflection is a concept of learning from experience that dominates teacher educator around the world. It is true that self-reflective is not a natural process since it needs critical thought, self-direction, and problem-solving with personal knowledge and self-awareness. The major premise of the study is that although teachers are repeatedly encouraged to reflect on their teaching and learning, they are unable to do so successfully. Photovoice is a valuable tool to engage teachers in reflecting their own lives outside the school, voice their perspectives and share with other teachers, students, and policymakers. Reflective practice is a model for many professional development platforms, including teacher (Farrel, 2008; Schön, 2017). For teachers, a reflective practice means to gather the data, principle, assumptions and use the materials as the basis of critical reflection of their teaching (Richards and Lockhart's (1994). This kind of reflection in the form of self-reflection gives an advantage for teachers to draw implications in the classroom and bring new atmosphere for their students. In this sense, reflection seems like a routine activity for any assigned teachers. However, reflective 
practice gives tense for teachers to do so since it needs critical thought, self-direction, and problem-solving (Gun, 2011; Gungor, 2016).

To help teachers to have more opportunities for having self-reflective, photovoice is a tool for developing critical thought, self-direction and problem-solving that related to everyday life being a teacher. Photovoice is a valuable tool to engage teachers in reflecting their own lives outside the school voice their perspectives and share with other teachers, students, and policymakers. The purpose of this research is to describe the use of photovoice as a tool for self-reflection to engage teachers in the knowledge of multimodal literacy. This action research believed that photovoice as a self-reflective tool enhances the awareness of teachers' awareness of the teaching and learning process.

\section{What is Photovoice?}

Wang and Burris introduced photovoice in 1997 talked about the globalhealth issues. Photovoice designed as participatory action research and based on the assumption that everybody is a professional on his or her field. Photovoice is a document taken by a camera and a description of the lives experiences and as the tool of critical view to advocate for social changes in their community (Wang, Morrel-Samuels, Hutchinson, Bell, \& Pestronk, 2004). The aim of the research with photovoice as the document is for shaping policies and highlights on individual and community action (Wang, 1999).

Photovoice has embarked to be used in educational research. It is beneficial because it is an engaging tool for students, teachers, and researchers in learning and implementing the idea in a classroom. By using photovoice that based on multimodal literacy, students, teachers, and researchers can discover more about the lives outside the schools. Their voice can be heard by classmates, other teachers, other researchers, and policymakers.

\section{Photovoice as Self-Reflection on Multimodal Literacy}

John Dewey, American educator on the year 1933 suggested that one of the main aims of education is helping people to have a habit of reflection as the activity of routine thought and actions. Related to recent years that the world faces many educational problems, Dewey (1933) in Farrel (2012) the reflective practice can be defined as "an active, persistent, and careful consideration of any belief or supposed form of knowledge in the light of the grounds that support it and further conclusions to which it tends that constitute reflective thought."

Reflective practice is a problematic process for teachers, since it demands critical thought, self- direction and resolving the problem in teaching and learning process (Gun, 2010). In trying to solve this problematic process of reflective practice, teachers look back at their classes and experiences outside of their classes and sketch implication for their classroom teaching. This action may in the form of self-reflection, where the thoughts, actions, and resolving problem come on routine activities for some teachers.

Photovoice is a participatory action research that through photos and pictures, teachers have chances of having selfreflective about the process of teaching, learning and sharing their knowledge and experience with their colleagues and students. Those activities from taking photos, having a critical thought, and resolving the problems risen from pictures or photos give a room for teachers to do selfreflective.

Photovoice as self-reflective practice gain valuable knowledge for teachers' growth, experiences sharing for their colleagues and students. These kinds of activities enhance teachers' professional development in the content of teaching and learning process both in the classroom and outside of the classroom. This action empowers the feeling of self-reflection that educate others about realities. 
Wang and Burris (1997) used SHOWeD Analysis in the research of using photovoice as the methodology. SHOWeD is the acronym for the series of questions that teachers answer as they analyze their photo:

$\mathrm{S}=$ What do you See here?

$\mathrm{H}=$ What is really Happening here?

$\mathrm{O}=$ How does this relate to Our lives for your life personally?

$\mathrm{W}=$ Why does this situation, concern or strength exist?

e = How could this image educate the community (class)?

$\mathrm{D}=$ What can we Do about it?

Those six questions related to the SHOWeD analysis on the photo that teacher chose gives a room for teachers to have narrative and critical answers. Related to the self-reflective practice, photovoice that used SHOWeD analysis can guide teachers to narrate what the picture or photo talk about. The teachers answer the SHOWeD questions and go deeper to think critically about what the issues related to the educational field.

In this digital era, multimodal literacy becomes a big issue in the world. Both teachers and students meet new challenges in teaching and learning process. As in the educational sector and as a professional, teachers may know better about multimodal literacies. Tan and Zammit (2016) described multimodal literacies as semiotic system namely linguistics: written and spoken language; visual, colors, vectors, image, framing, distance; audio: volume, pitch, tempo and sound; gestural: movement, speed, expression and body language; particular: proximity, direction, and objects on space.

Teachers may learn this new challenge to the knowledge of the multiliteracies through photovoice. The photovoice becomes a tool for teachers to know better and have experience in learning multimodal literacies and share with their students. The result of the learning process of multimodal literacies can be achieved by teachers in the process of self-reflective using Photovoice.

\section{The Previous Research on the Adaptation of Photovoice as Self-Reflection on Multimodal \\ Literacy}

There are some studies related to the use of photovoice as a tool for reflection on educational setting. The study conducted by Ziergiebel (2016) on her dissertation about participatory action research that photographs are multiliteracies that facilitate students and teachers to have networks of communication, comprehension, and cultural diversity and give potential and chances to explore identity, demonstrate what they are familiar with, and engage the topics the students and teachers concern about on 2017, the study conducted by Treadwell and Taylor found that photovoice is a useful instrument to help students on reflect performance and various matters on their lives and powerful encouragement tools for teachers to foster their students' learning.

Vecchio et al. (2017) also found in their research that visual methodologies or photovoice allow students to represent their own experience. This tool enables students to voice about themselves about their angles, learning desires, and intercultural knowledge and experience. The research also suggested that by photovoice, students learn the potential issue that may happen in the future and how to challenge them.

\section{METHODS}

Five teachers participated in this study. Three teachers are 20 years of teaching experience, and the other two teachers have ten years of teaching experience. All the participants work in 2 suburb schools in Java, Indonesia. The three teachers are English teachers, and two are non-English teachers. The participants work individual in having photovoice as selfreflective. These photovoice activities crossed 12 weeks. The participating teachers agreed on the extra task and used 
photovoice as self- reflection on multimodal literacy.

The teachers took pictures related to their daily activities, such as at school, activities related to the professional development program, or teaching and learning process in the classroom. Teachers did the SHoWED Analysis of each picture as self-reflection on multimodal literacy. In every four weeks, teachers have a discussion and sharing session what they did relate to the photovoice as self-reflective. The teachers gave the response the questionnaire about photovoice as selfreflective and were interviewed to obtain wealthier data on the issue. The depth interviews were audio recorded and transcribed. The photovoice, the responses to the questionnaire, and the depth interview were later used as the sources of data. All the participants' written assignments were manually coded. Member and assignments checking, suggested by Merriam (1998) were used to deal with the trustworthiness of the data because the data were exposed to all participants to give commentaries and review.

\section{RESULTS AND DISCUSSION}

\section{Photovoice of Multimodal Literacy with SHOWeD Analysis}

The five teachers learned a great deal about multimodal literacy for the first time. They felt that the topic is interesting since the advanced technology that both teachers and students give another challenge in teaching and learning process. The teachers said that the classroom is different from last decade since most of the students have mobile phones. The tool cracked student's attention from teacher explanation in the classroom. Teachers thought that they need to discuss how to solve the problem.

By learning multimodal literacy, teachers have new knowledge that learning materials are not only in text form. Teachers understand more about the multimodal literacy materials such as pictures, photos, body gestures, and audio. The multimodal literacy becomes a chance for teachers to create materials from their environment and self- reflective using their mobile phone.

From the interview with five teachers, all have agreed that having selfreflective on multimodal literacy using photovoice give challenges for them. The knowledge of multimodal literacies gives ideas for teachers to teach students using photovoice as the tool in delivering the material. The other reasons are having selfreflective on multimodal literacies using photovoice give a room for teachers to learn new things and share with other teachers, it develops teacher' continued professional development.

Teachers are encouraged to take pictures from their classroom or outside the classroom. It can be activities related to teaching and learning process, professional development, or some pictures related to real life. They wrote their experience based on the pictures that choose and write their self-reflective using SHOWeD analysis. It develops the awareness of teachers that teaching and learning process is not students' need, but also as teachers they may take pictures around them to learn and reflect values that can be shared with others. The following are the self- reflective of two teachers as in figure 1 and figure 2 : 


\section{The 62 $\underline{\text { nd }}$ TEFLIN Closing Seminar}

Name of Photographer \& Writer : Mr.G

Title of Photograph

: The $62^{\text {nd }}$ TEFLIN Closing Seminar

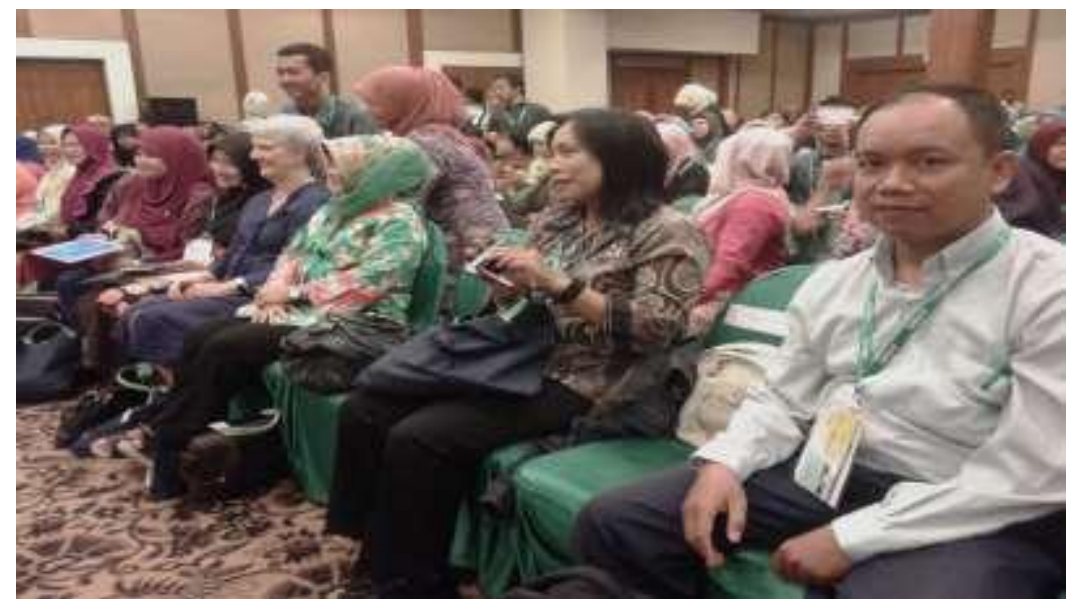

1. What is SEEN here? (Describe what the eyes see in the photo) The $62^{\text {nd }}$ TEFLIN closing ceremony in Lor In Hotel Solo

2. What is really HAPPENING?" (The unseen "story" behind the photo)

I joined the $62^{\text {nd }}$ TEFLIN in 2014 as a presenter. I presented the result of my classroom action research. That was my first time joined a conference which was not as easy as I thought before. I had to revise my CAR paper several times because it was not fill the requirement yet. So, I really tried so hard to accomplish my paper as well and finally my paper was accepted. The conference was conducted around 3 days and I bought 3 proceedings with my own money as much as Rp 950.000,00 which is for me it was quite expensive budget to join a seminar.

The English experts, Jack Richard and Anne Burn presented their work in the closing ceremony. The participants looked very happy in the last day because their responsibility to present was finally done. In the end of the event, many participants took some photos and videos to make some memories.

3. How does this relate to OUR lives? (Or MY life personally)

Seminar is one of the activities for teachers to have scientific publication. Teachers have responsibility to arrange lesson plan, conduct teaching-learning process, evaluate the learning, and follow up the evaluation. Through this forum, teachers are able to continue their progress by presenting their activities in the form of paper presentation and get feedback from others to have improvement.

4. WHY are things this way?"

I decide to pick this photo to motivate I myself to be better in doing my responsibility as an educator, especially to have a scientific publication.

5. How could this image EDUCATE people?"

The photo above can inspire the English colleagues to join the conference and present their paper in International forum. This gonna be an essential achievement and joy to meet the expert and new colleagues.

6. What can I DO about it?" (What WILL I or WE do about it?)

Facilitating the member of MGMP and I to have scientific publication. I hope that we can work together with English teachers in Sragen to make improvement in education.

Figure 1. Photovoice of Mr. G 


\section{The Change}

Name of Photographer \& Writer: Mr.T

Title of Photograph

: The Change

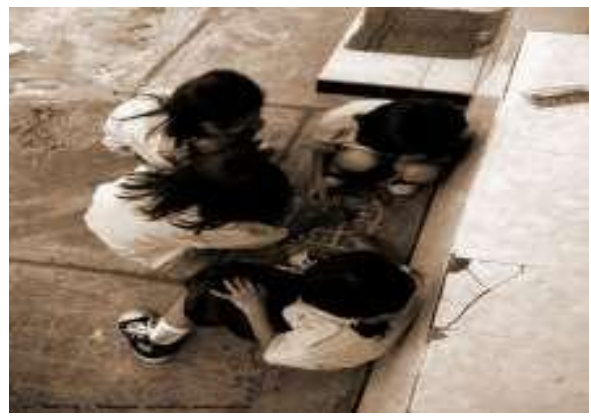

1. What is SEEN here? (Describe what the eyes see in the photo) Some children are playing the traditional game named tigan.

2. What is really HAPPENING?" (The unseen "story" behind the photo)

This picture was taken in 2014 at one of elementary school in Solo. Some students were playing tigan in which kids nowadays don't know what kind of game is it because this is too traditional and out of date. This time, children tend to make use of smart phone in every single time they have. However, kids on the picture above proudly share that playing this game is really interesting because they can have fun with their friends.

3. How does this relate to OUR lives? (Or MY life personally)

Technology looked like a tendency for human. They begin to distant the things that born before technology, for instance the intimacy with the family, playing simple game with their friends yet so joyful. Those activities slowly disappear because of the emergence of technology.

4. WHY are things this way?"

I decide to choose this photo to show that by having the simple game like this, we are able to find happiness.

5. How could this image EDUCATE people?"

Traditional game enable people to have healthy mind and attitude, not become a passive person toward others.

6. What can I DO about it?" (What WILL I or WE do about it?)

I plan persistently to educate people to take care of the relationship with others. This will lead to build up a good communication and improve the engagement of human. Another idea is to introduce traditional game to my students and advise them not to tend to smart phone because playing a real game able to encourage them to be more active socially.

Figure 2. Photovoice of Mr. T 


\section{Steps for Successful Use of Photovoice for Self-Reflective on Multimodal Literacy}

Teachers' experience with photovoice as a self-reflective tool on multimodal literacy is a new experience for the teachers. In the beginning, the researchers intended to use photovoice as a tool for learning multimodal literacies. In fact, there is another finding that the photovoice using $\mathrm{SHOWeD}$ analysis can be used as self-reflective that is good as teacher professional development.

This experience influenced all teachers that participated in this study. The teachers wanted to do more to the photovoice as a tool for learning multimodal literacies. We replanned and discussed the steps and hoped that there were better achievements for all of us. These are the steps of successful use of photovoice for self-reflective on multimodal literacies:

Step 1 is to discuss with teachers about photovoice, SHOWeD Analysis, selfreflective and multimodal literacies. Since the four things are new for teachers, researchers need to have discussion and forum to have the same perspectives about the four terms.

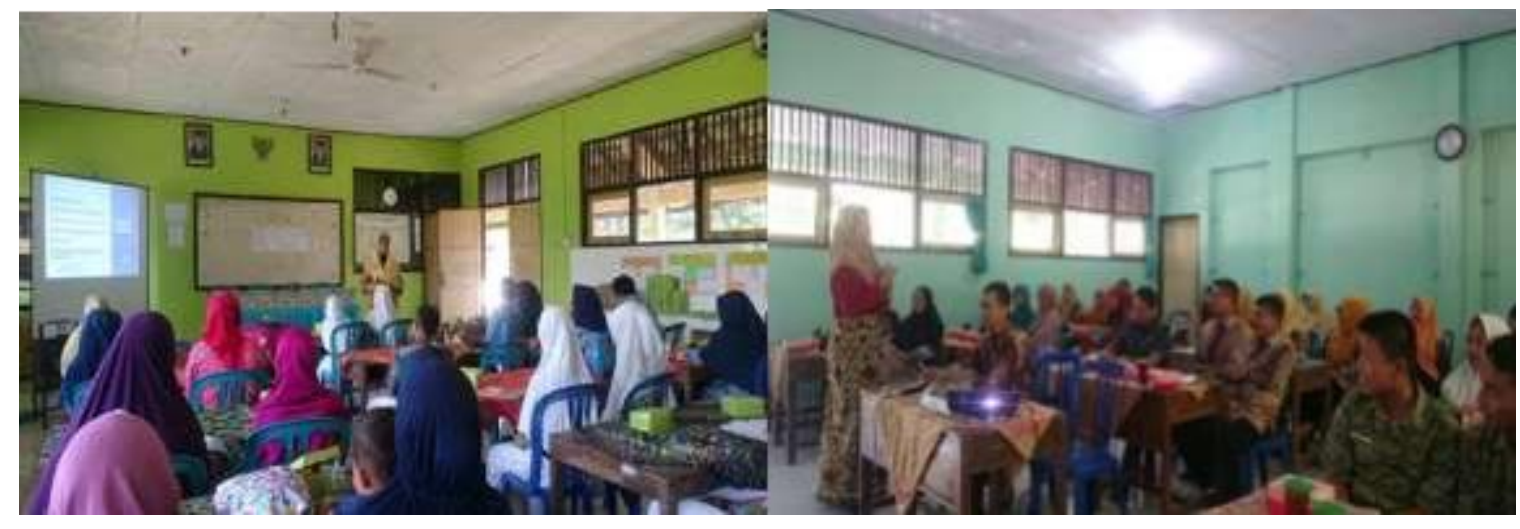

Figure 3. Initial Meeting about Photovoice as a Tool for Self-reflection

Step 2 is to select a topic. The initial step in implementing a photovoice becomes a tool for self-reflection on multimodal literacies that teachers want to explore more. The topic may vary from the classroom or outside of the classroom. It is essential for teachers that the topics give values and meaning so they will choose the pictures that have a voice for themselves, students and other teachers. They may discuss and assume that the picture they choose to analyze has a voice that can deserve to be heard.

Step 3 is to take photos. Teachers may use mobile phones for taking photos. They may take photos in the classroom or outside the classroom. Teachers may take photos from daily activities at home, or they may find some photos that they think the photos have values and meaning with our daily life.
Step 4 is to select and analyze the photo. Teachers may have 3-5 photos. They should choose the best photo that has a voice for themselves, students and also the other teachers. After choosing the photos, teachers analyze the photo using SHOWeD analysis. The researchers should encourage teachers to make sure that teachers have more profound thought about the photos and their voices can be heard by students and other teachers, such as motivate them to do better, and their photo has a voice that can be heard by policymakers. 


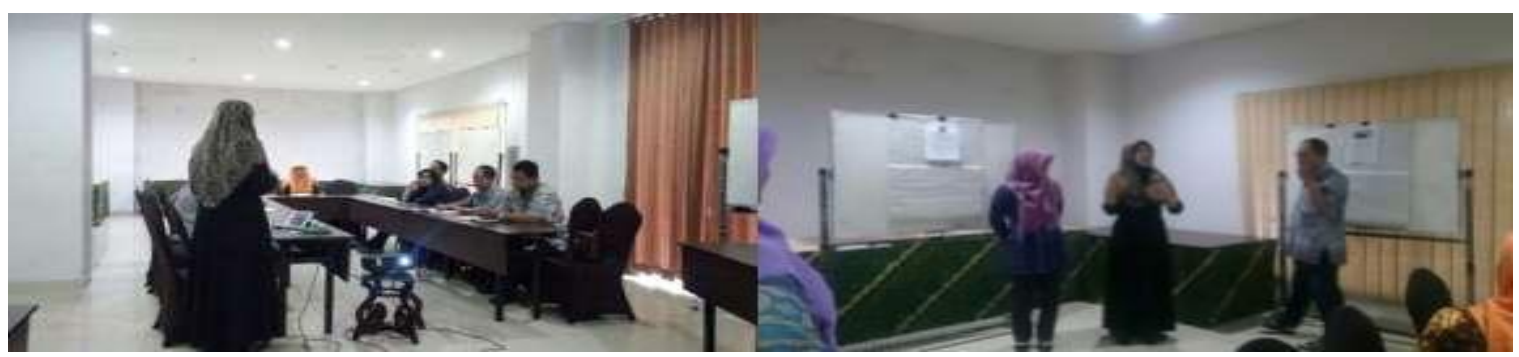

Figure 4. Discussing the Topic and Scaffolding the Term of Photovoice

Step 5 is to do literature circle. Teachers need to share their thought, their awareness, and their solving-problem by having literature circle. They discuss and share their experience by explaining and commenting on what the photos represent to other teachers. The literature circle as follows:

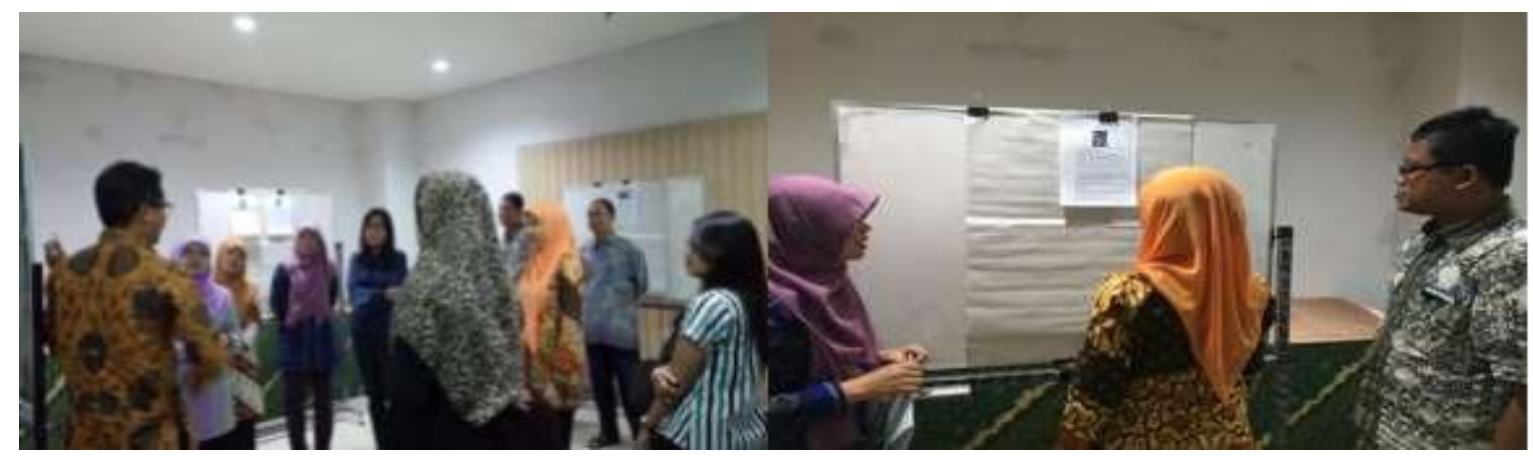

Figure 5. Literature Circle

Step 6 is to Advocate for change. The final step of this process is advocating the changes. This could be in small community. The teachers may share their knowledge, thoughts, and experiences through teachers' community or present the ideas to the conference. It is believed that this kind of sharing will motivate teachers to grow professionally and motivate other teachers to do the similar activity.

\section{CONCLUSION AND RECOMMENDATION}

Photovoice is a useful instrument for English teachers to know and implement it as self-reflective about multimodal literacy. Nowadays, with the technical advantages, multimodal literacy is a must study for teachers and implement it in the classroom. By knowing multimodal literacy such as pictures or photos, gestures, and other visual knowledge, teachers may use this instrument to grow themselves as professional teachers.
Photovoice can be a tool to think, act and have critical awareness about the multimodal literacy. Teachers may use their mobile phone as their daily tool to create multimodal literacy and use these photos to voice their perspectives and thought of their own experiences both in the classroom and outside of the classroom. Technology does not need to be a barrier to implementing photovoice as self-reflective for multimodal literacy. Teachers can take pictures anywhere, anytime, and situation. Every single photo will beneficial both for teachers and students and Tmay voice to the policymakers.

Finally, photovoice can be a powerful advocacy tool for teachers to promote themselves as learners through self-reflective activities about multimodal literacy. It enriches teachers with the thought, action and critical awareness that everything can be the source of the materials for learning. It changes the mindset about the opportunity to have various materials and 
also new learning experiences related to their lives in the classrooms.

\section{REFERENCES}

Farrell, T. S. C. (2012). Reflecting on reflective practice: (re)visiting Dewey and Schon. TESO Journal 3.1

Gun, B. (2010). Quality self-reflection through reflection training. ELT Journal

Gungor, M. N. (2016). Turkish pre-service teachers' reflective practices in teaching English to young learners.

Australian journal of teacher education, 41(2).

Merriam, S.B. (1998). Qualitative research and case study applications in education. San Fransisco, CA: Jossey-Bass.

Richards, J.C. and C Lockhart. (1994). Reflective Teaching in Second Language Classroom. Cambridge:

Cambridge University Press.

Schon, D.A. (1991). The Reflective Practitioner: How Professionals Think in Action. London: Routledge Treadwell, S. M., \& Taylor, N.
(2017). PE in pictures: using photovoice to promote middle school students' reflections on physical activity during free time. Journal of physical education,

Vecchio, L., Dhillon, K. K., and Ulmer, J. B. (2017). Visual methodologies for research with refugee youth.

Journal of intercultural education .vol 28, No. 2, 131-142

Wang, C. C. (1999). Photovoice: A participatory action research strategy applied to women's health. Journal of

Women's Health, 8, 185-192.

Wang, C. C., Morrel-Samuels, S., Hutchinson, P. M., Bell, L., \& Pestronk, R. M. (2004). Flint Photovoice: Community building among youths, adults, and policymarkers. American Journal of Public Health, 94, 911-913

Ziergiebel, A. M. (2016). Adolescent visual voices: discovering emerging identities through photovoice, perspective and narrative. Educational studies dissertation. 